\title{
Osmolality and Solute Concentration-Their Relationship with Oral Hydration Solution Effectiveness: An Experimental Assessment
}

\author{
RAUL A. WAPNIR AND FIMA LIFSHITZ \\ Department of Pediatrics, North Shore University Hospital, Manhasset, New York 11030, and Department of \\ Pediatrics, Cornell Universitv' Medical College, New York, New York, 10021
}

\begin{abstract}
The role of electrolyte, carbohydrate, and base composition, as well as osmolality, of oral hydration solutions (OHS), was investigated using a nonabsorbable marker and tritiated water in an in vivo intestinal perfusion system in rats. The OHS tested were the World Health Organization recommended formula, containing $90 \mathrm{mEq} /$ liter sodium and $111 \mathrm{mM}$ glucose, which was taken as the reference solution; five variants of this solution with different sodium and glucose concentrations; and two solutions without sodium, i.e. isotonic glucose and deionized water. Also tested were one solution with acetate in lieu of bicarbonate, and two commercial preparations where citrate substituted for bicarbonate. The best water absorption rates were obtained with World Health Organization-type OHS characterized by a combination of low osmolality and moderate sodium and glucose content. Hypotonic OHS $(190,220$, and $155 \mathrm{mosmol} / \mathrm{kg})$ in which the sodium:glucose ratios were $60: 30,60: 60$, and 30:55, respectively, produced mean jejunal water transport rates of 3.46, 3.20 , and $2.91 \mu \mathrm{l} / \mathrm{min} / \mathrm{cm}$, respectively, whereas the standard World Health Organization OHS (330 mosmol/kg) resulted in a rate of $1.36 \mu \mathrm{l} / \mathrm{min} / \mathrm{cm}(p<0.001)$. Similar good water absorption was achieved when Ac was the base ( $270 \mathrm{mosmol} / \mathrm{kg}$ and $60: 111$ sodium:glucose ratio) and with one of the commercial solutions $(245 \mathrm{mosmol} / \mathrm{kg}$ and 50:111 sodium:glucose ratio). The reference World Health Organization OHS allowed for sodium absorption, as did the OHS with sodium:glucose ratios of 90:45, 60:30, 60:60, and acetate-containing 60:111. Sodium at a concentration of $30 \mathrm{mEq} /$ liter or less resulted in the efflux of this electrolyte. High glucose concentration and lower osmolality exacerbated this effect. The results obtained in this investigation may assist in better evaluating OHS and in selecting modified formulae geared to specific hydration needs and possible replacement of water and sodium losses. (Pediatr Res 19: 894-898, 1985)
\end{abstract}

Abbreviations

OHS, oral hydration solutions

WHO, World Health Organization

Ac, acetate

The composition of OHS in use for the treatment of diarrhea has varied according to the type of etiologic agent involved, the availability of prepackaged or manufactured solutes to prepare

Received January 22, 1985: accepted April 11, 1985.

Correspondence Dr. Raul A. Wapnir, Pediatrics Special Studies Laboratory. North Shore University Hospital. Manhasset, NY 11030.
OHS, the cost factor, and other considerations (1-4). The most important points involved in the formulation of OHS have been sodium and carbohydrate concentrations and osmolality. The rationale for the amount of sodium, potassium, and chloride provided in the OHS has been related to the degree of potential electrolyte losses during the illness $(5,6)$.

Several field and experimental studies have tested the suitability of the OHS proposed by the WHO, containing $90 \mathrm{mEq} / \mathrm{liter}$ sodium, or of a variant with a lower sodium content (7-10). It is generally accepted that both can accomplish rehydration, with the WHO formula also allowing for the replenishment of sodium. The amount of glucose added $(20 \mathrm{~g} /$ liter or $111 \mathrm{mM})$ has been considered optimum.

Earlier reports had provided conflicting information on the stoichiometry of sodium:glucose cotransport and the fluxes of electrolytes and water, either from in vitro (11-14) or from in vivo studies, including animal experimentation $(15,16)$ and clinical trials $(16,17)$.

We previously evaluated the relationship between net water and sodium absorption in OHS and the concentration of sodium and glucose and osmolality in perfused rat jejunal loops (16). Optimization of net water absorption under isotonic conditions occurred at a 1:2 sodium:glucose ratio, while sodium absorption was always directly related to its perfusate concentration.

In this report we investigated the magnitude of net water absorption and unidirectional fluxes of water in relation to varying glucose and sodium concentrations, osmolality, and base composition in OHS, using the same animal model of in vivo jejunal absorption. Our data indicate that hypotonic solutions with a 1:1 or $2: 1$ sodium:glucose ratio yield even higher net water absorption. The replacement of acetate for bicarbonate improves the rehydration and sodium sparing performance of the OHS.

\section{MATERIALS AND METHODS}

Experimental animals. Male, Wistar-derived rats (Crl:WI:BR, Charles River Breeding Labs., Kingston, NY) weighing between 150 and $200 \mathrm{~g}$ were kept on a commercial diet upon arrival (Purina Lab Chow, Ralston Purina Co., St. Louis, MO) for 5 to 10 days, fasted overnight, and anesthetized with intraperitoneal urethane (Sigma Chemical Co., St. Louis, MO., $1.3 \mathrm{~g} / \mathrm{kg}$, single bolus). The rats were secured to lucite stages which were heated with electric pads. The animals maintained a rectal temperature between 36.5 and $37.5^{\circ} \mathrm{C}$ during the procedures. The abdomen was open and a 20 to $30 \mathrm{~cm}$ segment of the proximal jejunum was cannulated distal to the ligament of Treitz. After rinsing the intestinal loop with warm saline, the jejunum was perfused with the solutions described below at a rate of 0.18 to $0.20 \mathrm{ml} / \mathrm{min}$. After a $60-\mathrm{min}$ equilibration period, eight $15-\mathrm{min}$ perfusate fractions were collected and separately analyzed. At the end of the perfusion, the rats were exsanguinated and the length of the 
Table 1. Composition of oral hydration solutions with variable sodium:glucose ratios

\begin{tabular}{|c|c|c|c|c|c|c|c|c|c|c|c|}
\hline \multirow[b]{3}{*}{ Sodium (mEq/liter) } & \multicolumn{6}{|c|}{ Modifications of the WHO formula } & \multicolumn{2}{|c|}{$\begin{array}{l}\text { No sodium } \\
\text { solutions }\end{array}$} & \multicolumn{3}{|c|}{ Modified base solutions } \\
\hline & & & & & & & & $\underline{0}$ & 60 & 60 & 50 \\
\hline & $90^{*}$ & 60 & $\underline{90}$ & 60 & 60 & $\underline{30}$ & 0 & $\overline{0}$ & $\overline{111}$ & $\overline{139}$ & $\overline{111}$ \\
\hline Glucose $(\mathrm{mM})$ & $\overline{111}$ & $\overline{111}$ & $\overline{45}$ & $\overline{30}$ & $\overline{60}$ & $\overline{55}$ & $\overline{278}$ & $\left(\mathrm{H}_{2} \mathrm{O}\right)$ & $(\mathrm{Ac})$ & $(" P "))^{R_{+}}$ & $(" L ")^{R} \ddagger$ \\
\hline Sodium (mEq/liter) & 90 & 60 & 90 & 60 & 60 & 30 & 0 & 0 & 60 & 60 & 50 \\
\hline Glucose (mM) & 111 & 111 & 45 & 30 & 60 & 55 & 278 & 0 & 111 & 139 & 111 \\
\hline$(\mathrm{g} /$ liter $)$ & 20.0 & 20.0 & 8.1 & 5.4 & 10.8 & 10.0 & 50.0 & 0 & 20.0 & 25.0 & 20.0 \\
\hline Potassium (mEq/liter) & 20 & 20 & 20 & 20 & 20 & 20 & 0 & 0 & 20 & 20 & 25 \\
\hline Bicarbonate (mEq/liter) & 30 & 30 & 30 & 30 & 30 & 30 & 0 & 0 & & & \\
\hline Chloride (mEq/liter) & 80 & 50 & 80 & 50 & 50 & 20 & 0 & 0 & 50 & 50 & 45 \\
\hline Citrate (mEq/liter) & & & & & & & & & & 30 & 30 \\
\hline Acetate (mEq/liter) & & & & & & & & & 30 & & \\
\hline $\mathrm{pH}$ & 8.3 & 8.3 & 8.3 & 8.3 & 8.3 & 8.3 & $5-7$ & $5-7$ & 7.5 & 5.4 & 6.4 \\
\hline Osmolality (mosmol/kg) & 330 & 270 & 265 & 190 & 220 & 155 & 278 & 0 & 270 & 285 & 245 \\
\hline
\end{tabular}

* WHO formula.

+ Pedialyte RS (Ross Laboratories, Columbus, OH). Present formulation contains $75 \mathrm{mEq} / \mathrm{liter}$ sodium and $65 \mathrm{mEq} / \mathrm{liter}$ chloride.

+ Lytren (Mead Johnson Nutritional Division. Evansville, IN).

perfused intestinal segment measured under a 3-g tension. A minimum of five animals were used to test each perfusing solution.

Composition of solutions. The composition of the perfusing solutions utilized is shown in Table 1. For comparative purposes the WHO recommended OHS was taken as the reference. The solutions tested were: 1) variants of the WHO formula with different concentrations of sodium and glucose and decreasing osmolality, but the same levels of potassium and bicarbonate. The sodium:glucose ratios (mEq/liter:mM) were: 60:111, 90:45, $60: 30,60: 60$, and 30:55. 2) A $50 \mathrm{~g} /$ liter glucose solution $(0: 278)$ without electrolytes and deionized water (0:0). 3) A low sodium, WHO-type OHS, but where Ac substituted for bicarbonate, and two manufactured OHS, Pedialyte RS ("P"; Ross Laboratories, Columbus, $\mathrm{OH}$ ) and Lytren ("L"; Mead Johnson Nutritional Division, Evansville, IN).

Phenol red was added as a nonabsorbable marker to all solutions at a concentration of $20 \mathrm{mg} /$ liter. In addition, sufficient ${ }^{3} \mathrm{H}_{2} \mathrm{O}$ (New England Nuclear, Boston, MA) to provide 10,000 to $20,000 \mathrm{dpm} / \mathrm{ml}$ was included.

Analytical procedures. A. Net water absorption. This estimate was based on phenol red concentration differences. The concentration of phenol red was determined by a colorimetric method (18). A phenol red ratio was calculated from the quotient between the concentration of the dye in the perfusing solution and that in each fraction of the effluent. The net water fluxes were computed with the formula:

Net water absorption $(\mu \mathrm{l} / \mathrm{min} / \mathrm{cm})=\frac{(1-P R R) \times \text { I.R. } \times 1000}{\text { I.L. }}$

where I.R. = infusion rate in $\mathrm{ml} / \mathrm{min}$, I.L. $=$ intestinal length in $\mathrm{cm}$, and $\mathrm{PRR}=$ phenol red ratio.

B. Influx: Lumen-to-mucosa water movement. The calculation of the lumen-to-mucosa fluxes was based on the quantitation of labeled water disappearance in $\mu \mathrm{l} / \mathrm{min} / \mathrm{cm}$ and was estimated according to the formula:

$$
\frac{\left[\mathrm{dpm}{ }^{3} \mathrm{H} \text { Perf. } \times \text { I.R.]-[dpm }{ }^{3} \mathrm{H} \text { Effl. } \times \text { Effl. vol. }\right]}{\mathrm{dpm}{ }^{3} \mathrm{~h} \text { Perf. }} \times \mathrm{C} \times \mathrm{K}
$$

where $\mathrm{dpm}{ }^{3} \mathrm{H}$ Perf. = corrected $\mathrm{dpm} / \mathrm{ml}$ of perfusing solution; $\mathrm{I} . \mathrm{R} .=$ infusion rate in $\mathrm{ml} / \mathrm{min}$; $\mathrm{dpm}{ }^{3} \mathrm{H}$ Effl. $=$ corrected $\mathrm{dpm} /$ $\mathrm{ml}$ of each effluent; Effl. vol. = effluent volume in $\mathrm{ml} / \mathrm{min} ; \mathrm{C}=$ concentration of solute (for $\mathrm{H}_{2} \mathrm{O}=1$ ); $\mathrm{K}=1000$ I.L. This calculation assumes that the backflow of labeled material collected after a one-pass perfusion is negligible. ${ }^{3} \mathrm{H}_{2} \mathrm{O}$ was counted in a liquid scintillation counter (Beckman LS 3800, Somerset, $\mathrm{NJ})$.
C. Efflux: mucosa-to-lumen water movement. The computation of the mucosa-to-lumen efflux was estimated from the differences, in each collected fraction, between the influx and the net water absorption. The same assumptions postulated for the influx calculations on the differentiation between both unidirectional fluxes had also to be considered in this case.

$D$. Net solute absorption. The data were calculated with the formula:

$$
\text { [Solute] in Perf. - ([Solute] in Effl. } \times \text { PRR }) \times K^{\prime}
$$

where abbreviations are the same as those used above; $\mathrm{K}^{\prime}=$ $\frac{1,000}{\text { I.R. } \times \text { I.L. }} \times$ C.

The results were expressed as $\mathrm{nEq} / \mathrm{min} / \mathrm{cm}$, or nmoles $/ \mathrm{min} /$ $\mathrm{cm}$ when $\mathrm{C}$ was in $\mathrm{mM}$.

E. Laboratory determinations and analysis of data. The quantitation of sodium and potassium was carried out by flame photometry (Instrumentation Laboratory, model 143, Lexington, MA). Osmolality was determined by freezing point depression (Advanced Instruments, model 3C II, Needham Heights, MA). The statistical analysis of data was conducted applying one-way analysis of variance and Scheffe's test to estimate the critical differences between means. A probability of 0.05 was considered the threshold of significance (19).

\section{RESULTS}

Intestinal net water absorption was negatively correlated with the osmolality of the solution perfused (Fig. 1). The WHO formula with the highest osmolality had the lowest net water absorption across the jejunum. In contrast, all variants of the WHO OHS and commercial preparations with lower osmolality values had increased performance. The correlation coefficient, $r$, between osmolality and mean rates of water transport was $-0.796, p<0.02$. This relationship applied to all solutions tested except deionized water and the $278 \mathrm{mM}$ glucose solution.

Intestinal net water absorption was enhanced when glucose concentration in the OHS was reduced from $111 \mathrm{mM}$, as contained in the WHO solution, to between 30 to $60 \mathrm{mM}$, with sodium levels being maintained either at 60 or at $90 \mathrm{mEq} / \mathrm{liter}$ (Fig. 2). A comparable improvement in water absorption resulted when sodium was further decreased to $30 \mathrm{mEq} /$ liter, with glucose present in the OHS at $55 \mathrm{mM}$. In contrast, when sodium concentration was reduced in a WHO-type of OHS from 90 to 60 $\mathrm{mEq} /$ liter, net water absorption did not change appreciably if glucose was maintained at $111 \mathrm{mM}$.

An isotonic OHS containing glucose at $278 \mathrm{mM}$, but no 


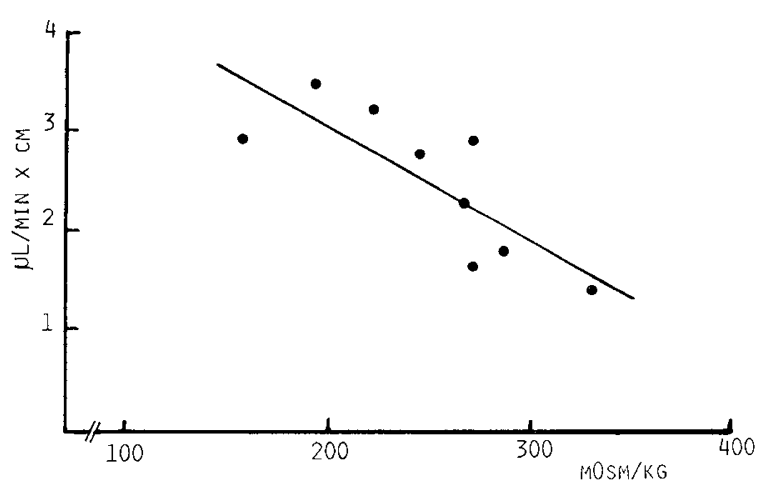

Fig. 1. Regression line between osmolality of OHS and the mean net water absorption rates of nine solutions (Table 1) perfused in vivo through rat jejunum (see "Materials and methods"). The data from the $278 \mathrm{mM}$ glucose solution and deionized water are not included. At least five animals and 40 determinations were used and analyzed for each point. The correlation between the two parameters was significant $(r=-0.792$, $p<0.02 . \mathrm{df}=7$ ).

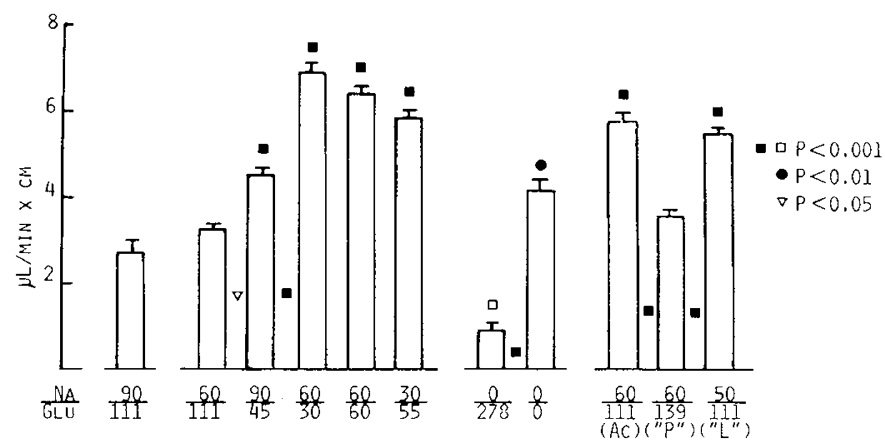

Fig. 2. Intestinal net water absorption rates (means \pm SEM) for OHS containing variable concentrations of sodium ( $N A$, in $\mathrm{mEq} /$ liter), and glucose ( $G L U$, in $\mathrm{mM})$. The first bar, representing the WHO standard solution, was used as the comparison (Scheffé test). The significance between adjacent hars is indicated by symbols between them. Filled symbols denote values greater than the reference OHS. Open symbols correspond to significantly lower values than the standard OHS.

sodium, was very ineffective in allowing net water absorption. Deionized water, without salts or carbohydrate, permitted a fair amount of water to be taken up by the mucosa; this occurred at a better rate than with the reference OHS, but was not as effective as the OHS containing sodium and glucose at ratios 60:30, 60:60, or 30:55 (Fig. 2).

Similarly an OHS, in which Ac substituted for bicarbonate as the base, ranked high in net water absorption. The same applied to formula "L." These two OHS performed better than "P," which, in turn, had a performance comparable to that of the WHO reference solution (Fig. 2).

The magnitude of sodium transport by rat jejunum with various OHS is shown in Figure 3. In WHO-type formulae sodium absorption was enhanced by OHS containing a sodium:glucose ratio of approximately $1: 1$ to $2: 1$. In contrast, lower sodium:glucose ratios, close to $1: 2$, resulted in net sodium secretion. This occurred both when the respective concentrations were $60: 111$ or $30: 55$, and the osmolality either 270 or $155 \mathrm{mosmol} /$ $\mathrm{kg}$. The two solutions which contained no sodium $0: 278$ and $0: 0$ ) induced a very considerable sodium efflux into the intestinal lumen (Fig. 3). Nevertheless, no sodium efflux occurred when either Ac or citrate were present in the OHS, even though the sodium:glucose ratios were close to $1: 2$. Both "P" and " $L$ " preparations were near equilibrium in terms of sodium absorption or secretion. Excluding water perfusions, a negative corre-

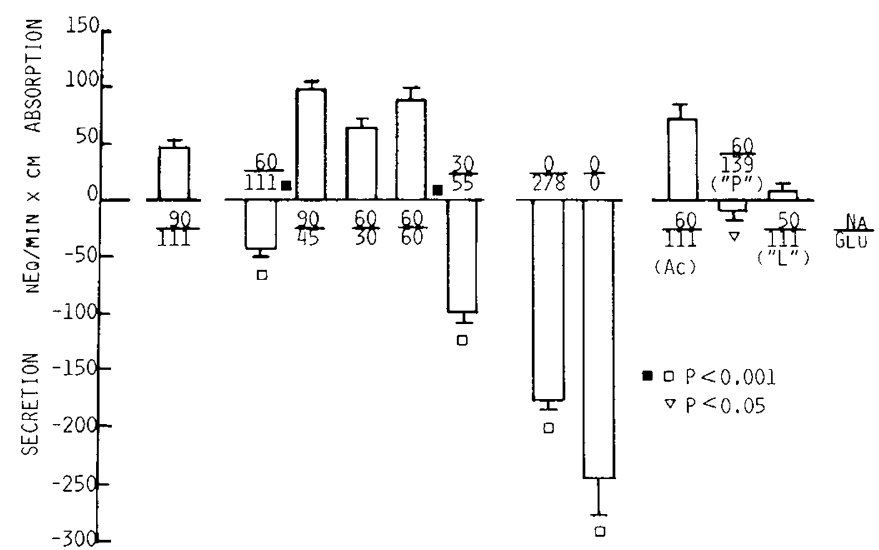

Fig. 3. Means \pm SEM of sodium absorption or secretion rates produced by the OHS described in Table 1 . The respective solutions are identified by their sodium ( $N A$, in $\mathrm{mEq} /$ liter) and glucose ( $G L U$, in $\mathrm{mM}$ ) concentrations. For procedural details, analytical methods and formulae used for the calculations, see the "Materials and methods" section. The abbreviations and symbols are the same as those used in Figure 2.
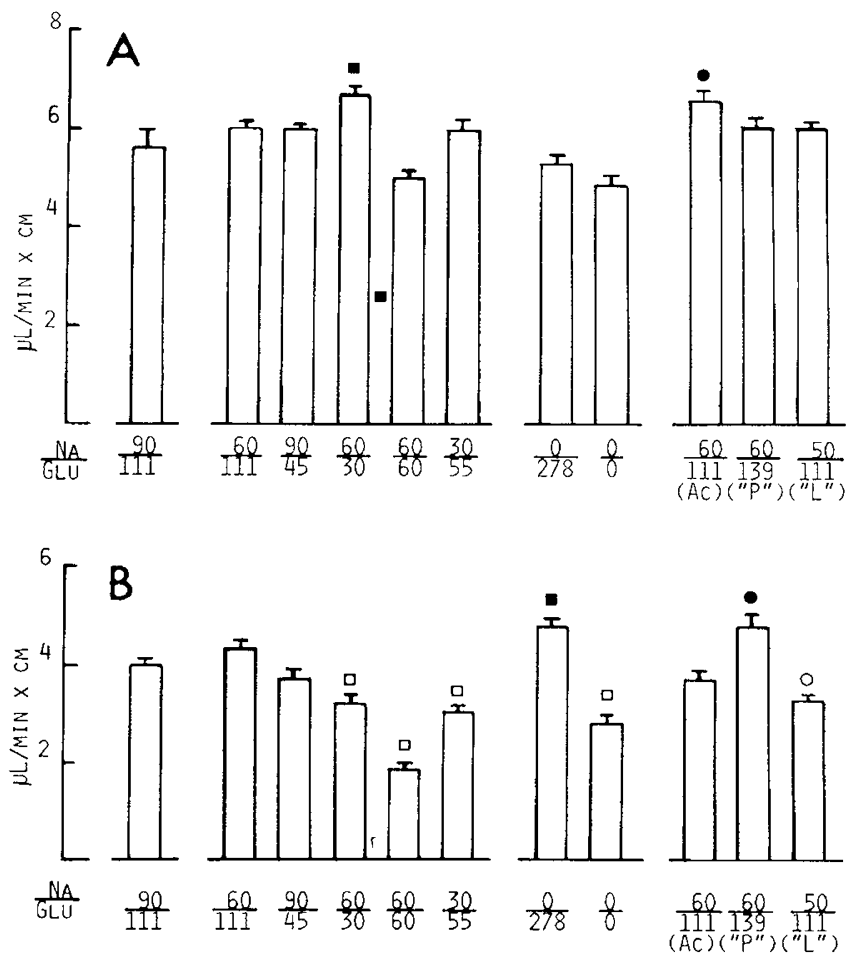

Fig. 4. $A$, water influx rates of the OHS listed in Table 1. The bars indicate the means \pm SEM. The formulae used for the calculations are described in the "Materials and methods" section. The abbreviations and symbols are the same as those of Figure 2. $B$, water efflux rates of the OHS listed in Table 1 . The bars indicate the means \pm SEM. The abbreviations and symbols are the same as those used in Figure 2.

lation could be established between sodium concentration and its absorption or secretion $(r=-0.897, p<0.05)$.

The net water absorption, as determined by changes in the concentration of a nonabsorbable marker, could be related to the water influx and efflux induced by the OHS perfused (Fig. 4 $A$ and $B$ ). Only the OHS prepared with a 60:30 ratio of sodium:glucose, and the Ac-containing OHS produced water influx rates significantly higher than those of the reference WHO solution (Fig. 4A). The rates of water efflux indicated that the better net absorptive performance of the solutions with low sodium and glucose contents was associated with a comparatively re- 


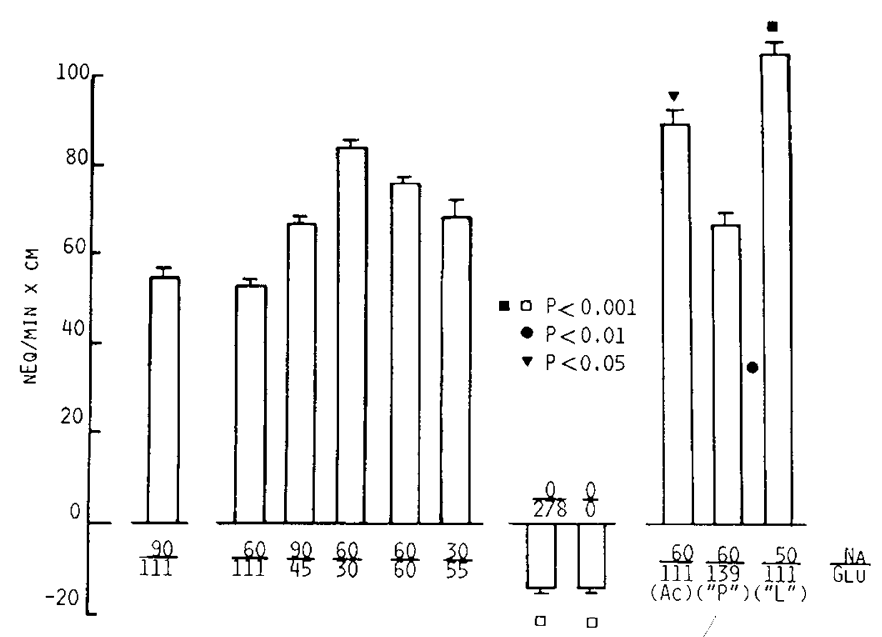

Fig. 5. Potassium absorption rates of the OHS perfused through rat jejunum, as described in "Materials and methods." The abbreviations and symbols are the same as those of Figure 2.

duced efflux of fluid (Fig. $4 B$ ). The same explanation could be provided in the case of deionized water and of formula "L." Conversely, the poor performance of isotonic glucose, and the average results obtained with formula "P" could relate to the significantly increased efflux exhibited by these two solutions as compared with the WHO recommended OHS.

All WHO-type variant OHS with $20 \mathrm{mEq} /$ liter of potassium produced absorption of this element at a comparable rate (Fig. 5). An OHS with the same concentration of potassium, but with Ac instead of bicarbonate, yielded a higher rate of potassium absorption. An even greater absorption rate of this cation was observed when "L" was perfused. However, this formula contains 25 rather than $20 \mathrm{mEq} /$ liter of potassium, as in the other salt containing OHS. The differences in potassium absorption exceeded the proportion between the concentration of this element in the two solutions, suggesting other factors have a role in determining absorption rates. As observed in the case of sodium, there was net potassium efflux in the two solutions with no electrolytes present. A significant positive correlation could be established between sodium and potassium transport rates $(r=$ $0.822, p<0.01$ ), for all the OHS tested, regardless of the concentration of salts or glucose.

\section{DISCUSSION}

The results obtained by intestinal perfusion in healthy rats of a variety of OHS reveal that solutions containing a combination of low osmolality and moderate sodium and glucose content have the greatest effect on net jejunal water absorption in vivo. An OHS with an osmolality around $200 \mathrm{mosmol} / \mathrm{kg}$ and sodium:glucose ratios up to $2: 1$, and a concentration of glucose not exceeding $60 \mathrm{mM}$ induced the greatest net water absorption across the jejunum.

It is well known that hyperosmolar solutions will stimulate water efflux and may even induce intestinal mucosal damage $(10,15,16)$. However, in this study we demonstrated a reduction of water absorption rates with solutions with an osmolality well within the physiologic range, and a significant inverse correlation between the osmolality of the solution perfused and the amount of jejunal water absorption. The decline in performance by OHS with higher osmolality as compared with those of lower osmolality suggest that, even in the isotonic range, increased osmotic gradients result in decreased water absorption rates, even when other factors such as sodium:glucose ratios remain constant. Since the net water absorption across the jejunum is determined by the relationship between water influx and efflux, the solutions with the best net water absorption were those which induced the highest influx and lowest efflux.
The decline in the performance of the $90: 45$ sodium:glucose formula, as compared with the 60:30 preparation suggests that even in the isotonic range, and with the same $2: 1$ ratio, increased osmolality is reflected in poorer experimental results, in agreement with concepts based on clinical practice (21). A higher glucose concentration in the OHS may be detrimental to the hydration process, even at isotonic levels $(15,16,22,23)$. Glucose at $278 \mathrm{mM}$ without sodium was a very poor inducer of water absorption. Thus, the attempt to provide additional energy supply to the patient with diarrhea during the hydration period could be potentially prejudicial. Whether be it by providing excess glucose, as such, or by addition of a complex carbohydrate with a potentially higher osmotic load, like corn syrup solids or other partially broken down starches, both approaches may result in less effective water absorption and more sodium losses. In diarrheal disease of infancy intestinal glucose transport is decreased (24), and there may be frequent intolerance to dietary carbohydrates, including monosaccharides such as glucose $(25)$ and partially hydrolyzed starch (26).

In addition to osmolality, the ratio of sodium to glucose in the OHS proved to be a key factor in the regulation of net water absorption. For variants of the WHO solutions, a decrease in glucose concentration from 111 to $30 \mathrm{mM}$ resulted in an improvement of water influx rates. The difference between the $60: 30$ and $60: 60$ sodium:glucose OHS was very significant. This finding may corroborate the postulated $2: 1$ sodium:glucose coupling involved in the transport of the monosaccharide (11-14). The estimates of sodium translocation indicates that a considerable uptake of this electrolyte could also take place at perfusion concentrations of $60 \mathrm{mEq} /$ liter, provided the level of carbohydrate present was within 30 to $60 \mathrm{mM}$. The precise cutoff point between secretion and absorption of sodium appears to be dependent on numerous variables $(16,27)$.

The preparation which contained $30 \mathrm{mM}$ Ac allowed for a higher net water absorption than a comparable OHS formulated with an equimolar amount of bicarbonate. This was also due to the additive effects of better water influx and less water efflux across the small intestinal mucosa. Moreover, the greater water and sodium influx associated with Ac could be due to a larger contribution of the electrochemically neutral sodium translocation mechanism by which Ac would be cotransported with sodium, as is known to occur for chloride (22); this would "drag" more water from the lumen to the mucosa.

The rationale for the use of Ac as a base is supported by these studies. Ac has been directly tested in field studies with a rate of clinical success not inferior to that obtained with the WHO recommended OHS (28). The Ac solution appeared remarkable in its capacity to allow for considerable absorption of both sodium and potassium, even at moderate electrolyte concentrations (Figs. 3 and 5). The possible reasons for this phenomenon could be related to one of several factors: a more physiologic $\mathrm{pH}$; a greater rate of anion uptake; a reaction between protons exchanged concomitantly with sodium absorption (29), and an additional absorption of nonionized acetic acid formed during the cation exchange, as well as a combination of these and other physiologically possible causes. The advantage of Ac over citrate in regard to sodium absorption is clear when comparing the Ac solution with "L," a preparation of similar osmolality and carbohydrate content, at close to physiologic $\mathrm{pH}$. Hence, the Ac solution seems to induce a significant sodium uptake at a concentration of this ion one-third lower than the typical WHO OHS.

A recent clinical trial has shown that a trisodium citrate containing OHS $(10 \mathrm{mM}=30 \mathrm{mEq} /$ liter $)$ and a total sodium concentration of $97 \mathrm{mEq} /$ liter was as effective as the standard WHO OHS in treating children and adults with diarrhea and in correcting acidosis (30). This report validates our experimental findings which showed that citrate, in concentrations up to 30 $\mathrm{mEq} /$ liter, did not adversely affect water absorption (16). It should also be noted that the trisodium citrate used in this study 
produces an OHS with a final alkaline $\mathrm{pH}$, close to that of bicarbonate containing solutions. The animal model for jejunal fluid and electrolyte absorption could be thus considered a good predictor for studying clinical applications.

The absorption of potassium presented similar characteristics in relation to osmolality as that of net water absorption, but appeared to be associated with sodium uptake when both cations were present. Our findings, therefore, conform with the concept of sodium-potassium transport linkage, as had earlier been postulated (31), which may be characteristic of active transport (32).

Although it is not warranted to directly extrapolate from the controlled, experimental condition to the clinical situation, the pointers provided by our study could suggest additional avenues for the treatment of infantile diarrhea. Even a rationale well understood for decades tends to be abandoned in favor of commonplace approaches imposed by limited resources in the field or by commercial standardization. It now seems appropriate to postulate that an OHS which could promote maximum net jejunal water absorption in vivo without sodium losses should be slightly hypotonic, with a sodium:glucose ratio of $2: 1$ to $1: 1$, and with a glucose concentration not exceeding $60 \mathrm{mM}$. The concentrations of sodium and glucose in the WHO formula which are, however, higher have been successfully used throughout the world during cholera epidemics and diarrheas of other pathogenesis. The advisability of the widespread use of $90 \mathrm{mEq} / \mathrm{liter}$ sodium solution has been debated $(3,33-36)$. Alternate water and OHS administration, as well as OHS with lower sodium and glucose concentrations have had their advocates $(3,4,37,38)$. This recommendation, in clinical practice, would result in a situation comparable to the OHS that produced in our experiments maximum net water absorption with little or no sodium losses. However, the strong sodium efflux occurring during plain water passage through the jejunum deserves cautionary consideration since it could be a potential physiologic stress to a possibly damaged mucosa.

Preliminary studies have indicated that the damaged intestinal mucosa has a diminished water and sodium absorptive capacity (39). Experimental protein-energy deficiency has also produced an altered condition in the juvenile rat (40). Optimization of OHS under these conditions may provide significant information for new clinical trials.

\section{REFERENCES}

1. Diarrheal Discase Control Program 1980 Guidelines for the Production of Oral Rehydration Salts. WHO. Geneva, Series 80.3

2. Parker RL. Rinehart W. Piotrow PT 1980 Oral rehydration therapy for childhood diarrhea. Popul Rep [L] 2:41-75

3. Hirschhorn $N 1980$ The treatment of acute diarrhea in children. An historical and physiological perspective. Am J Clin Nutr 33:637-663

4. Finberg L. Harper PA, Harrison HE, Sack RB 1982 Oral rehydration for diarrhea. J Pediatr 101:497-499

5. Carraza F. Nichols BL 1984 Oral hydration and feeding of the child with diarrhea. Clin Nutr 3:18-27

6. Mahalanabis D. Merson MH. Barna D 1981 Oral rehydration therapy: recent advances. World Health Forum 2:245-249

7. Harrison HE 1954 The treatment of diarrhea in infancy. Pediatr Clin North Am 1:335-348

8. Hirschhorn N. Kinzie JL. Sachar DB, Northrop RS. Taylor JD. Ahmad SZ. Phillips RA 1968 Decrease in net stool output in cholera during intestinal perfusion with glucose containing solution. N Engl J Med 279:176-181

9. Bart JK. Finberg L 1976 Single solution for oral therapy of diarrhea. Lancet
2:633-634

10. Nichols BL, Soriano HA 1977 A critique of oral therapy of dehydration due to diarrheal syndromes. Am J Clin Nutr 30:1457-1472

11. Goldner AM. Schultz SG, Curran PF 1969 Sodium and sugar fluxes across the mucosal border of the rabbit ileum. J Gen Physiol 53:362-383

12. Hopfer U, Groseclose R 1980 The mechanism of Na-dependent D-glucose transport. J Biol Chem 255:4453-4462

13. Kimmich G, Randles J 1980 Evidence for an intestinal Na-sugar transport coupling stoichiometry of 2.0. Biochim Biophys Acta 596:439-444

14. Kaunitz JD, Gunther R, Wright EM 1982 Involvement of multiple sodium ions in intestinal D-glucose transport. Proc Natl Acad Sci USA 79:23152318

15. Nalin DR, Ally K, Hare R, Hare K 1972 Effect of cholera toxin on jejunal osmoregulation of mannitol solutions in dogs. J Infect Dis 125:528-532

16. Lifshitz F. Wapnir RA 1985 Oral hydration solutions: experimental optimization of water and sodium absorption. J Pediatr 106:383-389

17. Sladen GF, Dawson AM 1969 Interrelationships between the absorption of glucose, sodium and water by the normal jejunum. Clin Sci 36:119-132

18. Fordtran JS 1975 Stimulation of active and passive sodium absorption by sugars in the human jejunum. J Clin Invest 55:728-737

19. Schedl HP, Clifton JA 1961 Small intestinal absorption of steroids. Gastroenterology 41:491-499

20. Bruning JL, Kintz BL 1977 Computational Handbook of Statistics, 2nd ed. Foresman Co, Glenview, pp 125-127

21. Finberg L 1981 Dehydration and osmolality. Am J Dis Child 135:997-998

22. Swabb EA, Hynes RA, Donowitz M 1982 Elevated intraluminal pressure alters rabbit small intestinal transport in vivo. Am J Physiol 242:G58-64

23. Swabb EA, Hynes RA, Marnane WG, McNeil JS, Decker RA, Tai Y-H, Donowitz M 1982 Intestinal filtration-secretion due to increased intraluminal pressure in rabbits. Am J Physiol 242:G65-75

24. Lifshitz F, Coello-Ramirez P, Gutierrez-Topete G, Corrado-Cornet MC 1971 Carbohydrate intolerance in infants with diarrhea. J Pediatr 79:760-767

25. Lifshitz F, Coello-Ramirez P. Guitierrez-Topete G 1970 Monosaccharide intolerance and hypoglycemia in infants with diarrhea. I. Clinical course of 23 cases. J Pediatr 77:595-603

26. Fagundes-Neto U, Viaro T, Lifshitz F 1985 Tolerance to glucose polymers in malnourished infants with diarrhea and disaccharide intolerance. Am J Clin Nutr 41:228-234

27. Meeuwise GW 1983 High sugar worse than high sodium in oral rehydration solutions. Acta Paediatr Scand 72:161-166

28. Patra FC, Mahalanabis D, Jalan KN, Sen A, Banerjee P 1982 Can acetate replace bicarbonate in oral rehydration solutions for infantile diarthoea? Arch Dis Child 57:625-637

29. Murer H. Hopfer U, Kinne R 1976 Sodium-proton antiport in brush border membrane vesicles isolated from rat small intestine and kidney. Biochem $\mathrm{J}$ 154:597-604

30. Islam MR, Samadi AR, Ahmed SM, Bardhan PK, Ali A 1984 Oral rehydration therapy: efficacy of sodium citrate equals to sodium bicarbonate for correction of acidosis in diarrhea. Gut 25:900-904

31. Rose RC 1976 Transport of sodium and potassium in intestinal epithelial cells. Life Sci 18:1229-1236

32. Sweadner KJ. Goldin SM 1980 Active transport of sodium and potassium ions. N Engl J Med 302:777-783

33. Aballi AJ 1975 Single solution not ideal for oral therapy of diarrhoea. Lancet 2:513-514

34. Nalin DR, Harland E, Ramlal A, Swaby D, McDonald J, Gangarosa R, Levine M, Akierman A, Antoine M, Mackenzie K, Johnson B 1980 Comparison of low and high sodium and potassium content of oral rehydration solutions. $J$ Pediatr 97:848-853

35. Pizarro D Posada G, Villavicencio N, Mohs E, Levine MM 1983 Oral rehydration in hypernatremic and hyponatremic diarrheal dehydration. Am J Dis Child 137:730-734

36. Saberi MS, Assaee M 1983 Oral hydration of diarrhoeal dehydration. Acta Paediatr Scand 72:167-170

37. Tripp JH, Candy DCA 1984 Oral rehydration fluids. Arch Dis Child 59:99_ 101

38. Finberg L 1984 Oral electrolyte-glucose solutions: 1984. J Pediatr 105:939940

39. Lifshitz F, Bayne MA, Teichberg S, Wapnir RA 1984 The damaged intestinal mucosa: strategies for selecting oral hydration solutions (OHS). Pediatr Res $18: 204 \mathrm{~A}$

40. Wapnir RA, Lifshitz F 1985 Protein-energy malnutrition: effects on the intestinal absorption of water and electrolytes. Pediatr Res 19:236A 